\title{
Slow euthanasia? The deaths of psychogeriatric patients
}

\author{
Dawn Black, David Jolley
}

\begin{abstract}
Psychogeriatric services reach out to people who are suffering from psychiatric disorders which may persist until death and may bring forward death. It has been suggested that these services should aim at avoiding admitting patients for hospital care whose lives may be ended by the upset of admission or prolonged by inappropriate nursing and medical interventions. A review of the characteristics of patients dying during one year while under the care of a psychogeriatric service showed that one in three died as a psychogeriatric inpatient, the remainder dying at home or as inpatients in a general hospital. Those dying as psychogeriatric inpatients differed in their clinical and social characteristics from those dying elsewhere and it seemed unlikely that they could have been cared for humanely without the resources of the hospital ward.

Psychogeriatric practice has many similarities to the work of hospices with other terminally ill patients, but the duration of the terminal illness and the needs arising from it are often more prolonged. Probably the management of dying among psychogeriatric patients will be improved if lessons learnt from other hospice practices are adopted.
\end{abstract}

\section{Introduction}

Specialist psychiatric services for the elderly have won popularity because they aim at being available to patients in their own homes and at enabling them to remain in or return to their homes while receiving treatment or supportive care. ' 2 Death and the care of the dying, however, are inescapable parts of psychogeriatric practice. Delirium is often symptomatic of severe, lifethreatening illness ${ }^{2+}$; the progressive dementias carry a reduced life expectation for all but the very old; and though the schizophrenias of old age do not seem to predict an early death, other "functional" disorders, most notably depression, probably do." Yet the role of these services in managing the deaths of their clients has been discussed only rarely. It is 14 years since Baker's emotive and challenging article decrying admission to psychogeriatric care as a cause of death in itself for some patients or a means of prolonging life inappropriately for others. Baker pleaded, "Cooperation between medical practitioner and social services should make it possible for the frail elderly to die in peace and dignity in their own homes, even if alone."

Services reaching out to patients suffering from other irrecoverable illnesses, notably cancer ${ }^{\star}$ and more recently AIDS, ${ }^{4}$ have confirmed that much can be done to help people and alleviate pain and distress while maintaining their place at home. Yet these hospice movements find that a specialist terminal care facility provides an essential component within their range of activity, and some patients die more easily in these facilities than in their own homes."

Roughly $65 \%$ of men and $74 \%$ of women of all ages die in hospital or other institutions, " and less than $36 \%$ of old people die in private households. ${ }^{12}$ So how practicable is Baker's exhortation and what is the usual experience of elderly patients known to be suffering from psychiatric disorder as they approach death?

\section{Subjects and methods}

We reviewed the deaths of patients known to the South Manchester Psychogeriatric Service during 12 months 1985-6 to establish the numbers of deaths, the settings in which they occurred, and the characteristics of the patients and modes of dying associated with different settings.

The psychogeriatric service in south Manchester had served an urban population containing 28000 elderly, which rose to 31000 after 1975. A simple service case register had been maintained throughout. ${ }^{12}$ Deaths of patients known to the register during the study period were investigated by using a standardised schedule to interrogate case notes, service staff, and others as appropriate. ${ }^{1+}$ Modes of death were divided into seven categories - namely, collapse and sudden death; acute illness followed by death within seven days; acute illness followed by death within 8-28 days; suicide; gradual deterioration over more than one month, ending in comfortable death; gradual deterioration over more than one month, ending in distressed death; and sudden massive loss of ability followed by prolonged debility to death. Case histories were collected to illustrate these modes of death. ${ }^{14}$

\section{Results}

During the study period the service was concerned with 910 patients, 426 who were referred during the year and 484 who were continuing under treatment from previous years. A total of 97 deaths occurred. Thirty patients died in their own homes (that is, private households $(n=19)$ or rest homes $(n=11)$, 35 in general hospital beds, and 32 in psychogeriatric beds. The age range of those who died was $75-84$, and women outnumbered men 66 to 31 . Less than one third of patients were still married at the time of death. Men and married people were underrepresented in rest homes. The age distribution was similar in all settings.

Patients dying at home were more likely to have lived with a fit spouse or in a rest home at the time of referral, whereas those who died in general hospital beds were more likely to have lived alone or with a frail spouse (table I). A third of all patients were known to the social services before referral. The 30 patients who died at home were more likely to have been using day centres (nine patients) and made little use of services to their homes (three had home helps, one used meals on wheels). The 35 patients dying in general wards had rarely attended day centres (two patients) but received services at home (11 had home helps, six used meals on wheels). The 32 patients ending their days in psychogeriatric wards may have been offered care but
Correspondence to:

Dr Jolley. 
TABLE I-Social circumstances of patients at time of referral

\begin{tabular}{lrccc}
\hline & \multicolumn{4}{c}{ Place of death } \\
\cline { 2 - 4 } $\begin{array}{l}\text { Residence and social } \\
\text { circumstance }\end{array}$ & Home & $\begin{array}{c}\text { General } \\
\text { ward }\end{array}$ & $\begin{array}{c}\text { Psychogeriatric } \\
\text { ward }\end{array}$ & Total \\
\hline Private home alone & 10 & 17 & 8 & 35 \\
Private house with fit spouse & 8 & 4 & 8 & 20 \\
Private house with frail spouse & 0 & 7 & 4 & 11 \\
Private house with other & 4 & 4 & 5 & 13 \\
Residential care & 8 & 3 & 5 & 16 \\
NHS long stay ward & 0 & 0 & 2 & 2 \\
\hline Total & 30 & 35 & 32 & 97
\end{tabular}

Difference between patients dying at home and in general ward significant at $5 \%$ level $\left(\chi^{\prime}=12 \cdot 108 ; \mathrm{df}=4\right)$.

There was no significant difference between profiles of patients dying at home and in psychogeriatric ward or between those dying in general ward and in psychogeriatric ward.

TABLE II - Mode of death

\begin{tabular}{lrrrr}
\hline & \multicolumn{4}{c}{ Place of death } \\
\cline { 2 - 5 } & Home & $\begin{array}{c}\text { General } \\
\text { ward }\end{array}$ & $\begin{array}{c}\text { Psychogeriatric } \\
\text { ward }\end{array}$ & Total \\
\hline Mode of death & 12 & 4 & 1 & 17 \\
Collapse/sudden & 6 & 8 & 4 & 18 \\
Illness less than 7 days & 2 & 10 & 5 & 17 \\
Illness 8 days to 1 month & 3 & 0 & 0 & 3 \\
Suicide & 5 & 6 & 14 & 25 \\
Prolonged deterioration & 1 & 7 & 8 & 16 \\
$\quad$ comfortable) & 1 & 0 & 0 & 1 \\
$\begin{array}{l}\text { Prolonged deterioration } \\
\quad \text { distressed) }\end{array}$ & 30 & 35 & 32 & 97 \\
Unknown & & & &
\end{tabular}

Difference between patients dying at home and in general ward significant at $1 \%$ level $(\gamma=17 \cdot 931 ; \mathrm{df}=6)$.

$1 \%$ level $(\chi=17.931 ; \mathrm{df}-6)$. Difference between patients dying at hom
significant at $0 \cdot 1 \%$ level $(\chi=24 \cdot 662 ; \mathrm{df}=6$.

significant at $0 \cdot 1 \%$ level $(\chi=24 \cdot 662 ; \mathrm{df}=6)$. There was no significant differe and in psychogeriatric ward.

TABL.E III - Length of time known to psychogeriatric service before death

\begin{tabular}{lcccc} 
& \multicolumn{4}{c}{ Place of death } \\
\cline { 2 - 4 } Length of time known & Home & $\begin{array}{c}\text { General } \\
\text { ward }\end{array}$ & $\begin{array}{c}\text { Psychogeriatric } \\
\text { ward }\end{array}$ & Total \\
\hline 0-3 Months & 3 & 11 & 0 & 14 \\
4-12 Months & 6 & 6 & 7 & 19 \\
13-24 Months & 8 & 5 & 4 & 17 \\
25-36 Months & 3 & 2 & 3 & 8 \\
37-48 Months & 5 & 3 & 4 & 12 \\
49-60 Months & 0 & 2 & 0 & 2 \\
Over 5 years & 5 & 6 & 14 & 25 \\
\hline Total & 30 & 35 & 32 & 97 \\
\hline
\end{tabular}

Difference between patients dying in general ward and in psychogeriatric ward significant at $5 \%$ level $(\%=16.630 ; \mathrm{df}=6$.

There was no significant difference between patients dying at home and in general ward or between those dying at home and in psychogeriatric ward.

rarely used any (one attended a day centre, three had home helps, three used meals on wheels). Seventeen of the patients who died at home, 24 of those dying in general wards, and 26 of those dying in psychogeriatric wards were suffering from dementia.

Many patients were known to be suffering from old or quiescent physical illnesses, 66 of the 97 patients having two or more problems. Multiple disorders were most evident among those who died in general wards, three or more problems being identified in 14 of these 35 patients as compared with 12 of the 62 dying elsewhere. New disorders contributing to death were more often single and were usually respiratory in general wards (20/35 cases) and psychogeriatric wards (23/32) and cardiovascular at home (14/30). Prescriptions for physical illnesses were rare among patients dying at home (11 patients) but more common in hospital (22 patients in psychogeriatric wards, 32 in general wards).

Bronchopneumonia was the commonest certified cause of death. It accounted for 22 of the 32 deaths in psychogeriatric wards and was the predominant cause of death in other hospital beds (16/35 cases). Circulatory causes of death were seen most frequently at home (14 cases) and were the second commonest cause in both general wards (10 cases) and psychogeriatric wards (six). Neoplasms seemed less important than national statistics suggest, ${ }^{15}$ being responsible for seven of the deaths in general wards but only two deaths in psychogeriatric wards and one death at home.

Cause of death does little to reflect the experience of the patients or the nursing requirements as death approaches. Many of those who died at home did so with little or no warning, death coming suddenly to 12 patients and occurring within a week of onset of the terminal illness in a further six. The process of dying was fairly short in general medical wards: four patients died suddenly and a further eight died within a week; in all 22 of the 35 patients were dead within a month of onset of their terminal illness. The picture was different in psychogeriatric wards. In these wards the death of 22 of the 32 patients took more than a month from the time of onset of their terminal decline, and over a third of these had protracted deaths characterised by distress, pain, or other discomfort (table II).

Many patients had been known to the psychogeriatric service for a long time; only 33 were within their first year of contact. Twenty one of the patients dying at home and 25 of those dying in psychogeriatric beds had been receiving treatment and support for over a year, and five and 14 patients in these two groups respectively had been receiving treatment and support for over five years. Even among the patients dying in general wards (10 of whom were referred during the terminal admission) 18 had been known for more than a year and six for over five years (table III).

Many of those dying at home had been supported with minimal recourse to psychogeriatric hospital facilities. Two thirds had never been admitted and only a quarter had used the day hospital. Their support and treatment had been through outpatient attendances and home visits by doctors and community psychiatric nurses or social workers from the unit, or both. Similarly, only a third of those dying in general wards had previously become psychogeriatric inpatients and a third had used the day hospital.

Clearly all patients dying in psychogeriatric wards had been inpatients at least once, but in 14 cases this was not their only admission. In addition, 16 patients had attended the psychogeriatric day hospital. Interestingly, day hospital care had "failed" within one month in three of these patients, whereas early failure was not seen among patients dying elsewhere. Indeed, seven of the patients dying at home had been attending the day hospital for more than a year compared with only four of those dying in psychogeriatric wards.

\section{Discussion}

Death is a common occurrence in psychogeriatric practice, one in 10 patients managed by our service dying within a year. Many other psychogeriatric services operate in a similar way and may have similar experiences. Seeing patients (and their relatives) through to the end is not a simple or short run task."

Isaacs $e t$ al introduced the concept of "predeath" to focus attention on life that continues despite crippling, sometimes progressive disability for many elderly people before they finally die. ${ }^{10}$ Many of our patientscertainly all those suffering from dementia-had entered predeath by the time that they were referred to us. Yet many were able to spend much of their remaining time at home. Only 14 of 64 patients who had been under care for more than a year spent more than their last 12 months in a psychogeriatric bed.

Possibly unknowingly, psychogeriatric services 
respond to clients in much the same way that hospices do to their more traditionally "terminally ill" patients. And in the same way that hospices might aim at helping people die at home with minimal distress but find that some are best managed at the end within the hospice, so too do psychogeriatric services. The third of psychogeriatric patients needing this form of terminal care may be characterised as suffering from dementia, physically quite fit, surviving for a long time after referral, coming from fairly resourceful homes or rest homes, and "failing" despite offers of care and support at home, including day hospital care. By virtue of these characteristics these patients differ from the remaining two thirds, who can be helped to die at home, in rest homes, or during the course of fairly brief admissions to general hospital wards. A blanket approach such as Baker's, which insists that no one should die in long stay psychogeriatric wards, ${ }^{7}$ cannot be sustained in the face of these different needs and characteristics.

Life and death in long stay care present many difficulties. For half of our patients the terminal admission lasted over five years. Over two thirds of patients lingered just short of death for many weeks, and half of these protracted deaths featured distress with or without pain. In all these cases the patient, his or her family, and the nursing staff received the support of the full multidisciplinary team, including senior doctors, physiotherapists, social workers, and others. Nevertheless, it is our impression on reviewing our own practices that the medical management of the deaths was less positive than it might have been. In particular, it was highly unusual for morphine or similar narcotics to have been used to relieve distress until the very last.

There is a culture of protectiveness towards the limited life and quality of life available to patients in a long stay psychogeriatric ward. It is so easy for casual observers to judge all such existence of no worth that any intervention that might appear to substantiate such a view by snuffing out that life becomes alien and banished from thought and practice. Possibly here also we should recognise lessons to be learnt from practitioners of the hospice approach, who have shown that morphine reduces distress even in the absence of pain and may prolong life by virtue of making it more tolerable.

1 Arie $T$. The first year of the (iendmaye's psychiatric service for old people. Lancet 1970;ii:1179-82.

2 Arie T, Jolley D. Making services work. In: Levy R, Post F, eds. The psychiutry of late life. Oxford: Blackwell Scientific, 1982:222-51

3 Roth $\mathrm{M}$. The natural history of mental disorder in old age. Fournal of Mentel Science 1955;101:281-301

4 Jolley D. Acute confusional states in the elderly. In Coakley D, ed. Acue geriatric medicine. London: Croom Helm, 1981:175-89.

5 Christic AB Survival in dementia: a review. In: Arie $T$, ed. Recomedsunes in psychogeriutrics. London: Churchill Livingstone, 1985:33-44

6 Murphy E, Smith R, Lindesay J, Slattery J Increased mortality rates in late life depression. Br f Psychiatry 1988;152:347-53.

7 Baker A. Slow curation " Br Med $\mathcal{f}$ 1976;ii:571-2.

8 Saunders C, Summers DH, Teller N. Hospice: the living idea. London: Edward Arnold, 1981.

9 Bates T, Hoy AM, Clarke DG, Laird PP. The St Thomas' Hospital terminal care support team. A new concept of hospice care. Lancet 1981;i:1201-3.

10 Hinton J. Comparison of places and policies for terminal care. Lancet 1979;i:29-33.

11 Office of Population Censuses and Surveys. Mortality statistics: place. London HMSO, 1986. (Series DHI, No 17.)

12 Cartwright A, Anderson J, Hockey L. Life hefore death-social studies in medical care London: Rouledge and Kegan Paul 1973.

13 Jolley D. All is not lust. In: Muacher M ed. New methods of mentul heulth are London Mer per 1979:195-207.

14 Black D. The clinical and social circumstances of patients dving in psychogeriatric care. Manchester: University of Manchester, 1988. (MSc thesis.

15 Office of Population Censues and Surveys. Mortality statistics: cause. Table 2. London: HMSO, 1985. (Series DH2, Noll.

16 Isaacs B, Gunn J, McKechan A, McMillan I, Neville Y. The concept of pre-death. Lancet $1971 ; 1: 1115-8$

17 Walsh TD, Smith M, Summers DH. Hospice care in motor neurone disease. Br.Med f 1976;ii:605.

(Accepted 6. Murch 1990)

\section{ANY QUESTIONS}

\section{Do water filtration devices improve the safety of tap water?}

In general public water supplies in the United Kingdom are maintained to a high standard and do not require further treatment. Nevertheless, some recent untoward incidents have raised doubts in consumers' minds and interest in the value of filtration devices for removing possible health hazards. Water filters can be obtained both for fitting in line to the drinking water supply (or on to the tap) and as portable (jug type) filters. Some are designed primarily to remove chemicals and objectionable tastes while others are intended to remove harmful microbes.

There have been few independent reports on the effectiveness of such filters. Tests on several jug filters (containing activated carbon and ion exchange resins) showed variable results in reducing aluminium concentrations with little effect on nitrates. Lead, and those organic compounds tested, were effectively removed, as was most of the chlorine. Although most of the filters contained silver to inhibit bacterial growth, this did not prevent bacteria from appearing in the filtered water after a week's use.' Other tests on three types of silver impregnated activated carbon filters designed to remove sediment, objectionable tastes, and some chemicals showed that the bacterial counts in the effluent increased over three weeks of use; Pseudomonas aeruginosa was isolated from all the filter effluents at some time during the test period.

Some ceramic, silver impregnated filters have been shown under test conditions to remove bacteria quite effectively, and these may improve the microbiological quality of a small private supply if used correctly. Other ceramic filters have passed bacteria through after a short period of use.

There is no current British Standard for domestic water filters, and while some will fulfil the manufacturer's claims for at least the early part of their life others are not reliable. In some instances complaints about misleading advertisements have been upheld by the Advertising Standards Authority.

The variability of the chemical characteristics of water supplies-for example, for plumbosolvency - and in the performance of the filters makes it difficult to assess their overall value in terms of health effects. What may be regarded as a desirable removal of certain chemicals from some waters could be balanced by the unwanted removal of beneficial minerals; bacterial overgrowth is likely to be a further problem. I am, however, not aware of any reported adverse effects arising from the use of such devices. - J V DADSWELl, director, Public Health Laboratory, Reading 1 Anonymous. Water worth drinking. Which? London: Consumers' Association, February
1989:58-62.
2 Tobin RS, Smith DK, Lindsay JA. Effects of activated carbon and bacteriostatic filters on
microbiological quality of drinking water. Appl Enctron Microbiol 1981;41:646-51.
3 Advertising Standards Authority. Case report 161. London: Advertising Standards Authority, 1988

A woman in her 30s with severe diabetes has renal failure and is receiving continuous peritoneal dialysis. She complains of restless and painful legs. What might be the cause and what treatment is advised?

This patient, with diabetic nephropathy and receiving continuous peritoneal dialysis, has, apparently, two complaints: restless legs and leg pain. The restless legs syndrome, which is now usually confined to patients receiving peritoneal dialysis, is an inability to find a comfortable position to rest the legs because of a crawling, prickling pruritus chiefly of the distal portion of the limb.' There are no physical signs: the syndrome is not considered to be a neuropathy. An explanation of the symptoms is unknown. Quinine, clonidine, and short acting benzodiazepines have been recommended but are of no use. The syndrome resolves after successful kidney transplantation. Leg pain in a diabetic patient suggests a neuropathy or vascular disease. Physical signs confirm the diagnosis. ROGER GABRIEL, renal physician, London

1 Callaghan N. Restless legs syndrome in uremic neuropathy. Neurologv 1966;16:359-61. 